\title{
MOOCS, GAMIFICAÇÃO E MOODLE: UMA INTEGRAÇÃO POSSÍVEL?
}

\author{
PORTO ALEGRE/RS JUNHO/2018
}

\author{
Elisângela Ribas - UFSM - elisangela.ribas@gmail.com \\ Júlia Marques Carvalho da Silva - IFRS - julia.silva@ifrs.br \\ Maria Isabel Acccorsi - IFRS - maria.accorsi@ifrs.edu.br \\ Tipo: Relato de Experiência Inovadora (EI) \\ Categoria: Métodos e Tecnologias \\ Setor Educacional: EDUCAÇÃO MÉDIA E TECNOLÓGICA
}

\begin{abstract}
RESUMO
A gamificação pode ser definida como a aplicação de conceitos de jogos no ambiente de aprendizagem. Pesquisas anteriores mostraram que a gamificação tem um impacto positivo no engajamento dos alunos e estimula a interação entre os alunos. Este artigo apresenta os desafios de incorporar técnicas de gamificação em curso curso online de formato massivo e aberto. Nosso objetivo é o de explorar a possibilidade de usar técnicas de gamificação em cursos online quando o número de alunos é muito grande. O principal desafio em incorporar a gamificação na aprendizagem é investimento para construção de um modelo pedagógico viável e de baixo custo.
\end{abstract}

Palavras-chave: plugins, restrições, gamificação, recompensa, MOOC 


\section{Introdução}

A aprendizagem online está se expandindo em termos de disponibilidade e popularidade, contudo são evidenciadas altas taxas de evasão, problema que precisa ser superado (LEE, CHOI; 2011). Estudos sobre a retenção de alunos virtuais em cursos online propõem diferentes estratégias para manter o interesse dos alunos nos cursos e preservá-los até sua conclusão.

Durante os últimos anos, a gamificação tem recebido muita atenção, pois apoia o engajamento e contribui para conclusão de atividades e para interação dos alunos, o que pode favorecer suas aprendizagens. A gamificação como estratégia para aumentar a taxa de retenção e para promover o envolvimento dos alunos tem sido objeto de estudo (FERNANDES, MARTINS, 2016; KRAUSE et al, 2015; OVERBY, 2011, NAWROT, DOUCET, 2014).

A principal contribuição do nosso estudo é apresentar os desafios de projetar um curso online usando técnicas de gamificação como um mecanismo para o engajamento dos alunos. O objetivo consiste em aplicar a técnica de recompensa a partir da utilização de questionários com uso das Restrições no Moodle. O desenho do curso foi destinado a apoiar a preparação dos alunos para as provas do processo seletivo de ingresso no Instituto Federal do Rio Grande do Sul. No geral, o estudo pretende responder à seguinte pergunta de pesquisa: "É possível criar um curso usando técnicas de Gamificação no Moodle, considerando um grande número de alunos?".

\section{Contextualização do estudo e caracterização dos participantes}

O estudo foi realizado em cursos preparatórios a distância para o processo seletivo de ingresso nos cursos de Ensino Médio, cursos de nível médio e cursos superiores do Instituto Federal de Educação do Rio Grande do Sul, IFRS, que acontece por meio de prova própria. As primeiras ofertas dos cursos preparatórios, chamados de Pré-IFRS, objeto deste estudo, foram voltadas aos inscritos nos processos seletivos vigentes da própria instituição, mas a partir de análise sobre a participação dos interessados e com vistas a oportunizar a preparação de candidatos em outros processos seletivos, o curso foi ampliado e atualmente é aberto para a comunidade em geral. "O Pré-IFRS tem dois objetivos: 1) apoiar o estudante na sua preparação para o Processo Seletivo do IFRS, na modalidade prova própria, e 2) apresentar o IFRS ao candidato (IFRS, 2018). Os cursos são organizados em módulos, sendo eles: Conheça o IFRS: informações sobre o IFRS; Matemática e suas Tecnologias: conhecimentos da área da matemática; Humanas e suas Tecnologias: conhecimentos das áreas de história, geografia, sociologia e filosofia; Natureza e suas Tecnologias: conhecimentos das áreas de biologia, química e física; Linguagens e suas Tecnologias: conhecimentos da área da língua portuguesa (língua inglesa e espanhol são ofertadas apenas para os candidatos de cursos de graduação). 
Em todos os módulos são disponibilizadas questões de provas simuladas e discussões em fóruns. A evolução dos estudos sobre os modelos pedagógicos para cursos online oportunizou que a equipe de Educação a Distância do IFRS desenvolvesse um modelo de curso baseado nos MOOCs. O modelo desenvolvido contou com automatização dos recursos disponibilizados, como conteúdos e atividades, a fim de efetivar um curso gamificado, aberto, massivo e online.

Existem três tipos de cursos no Pré-IFRS, aqueles que são destinados às provas de ingresso no ensino médio, ingressos em cursos de nível médio (subsequentes) e de graduação. No caso do ensino médio, a exigência é ter concluído o ensino fundamental, enquanto que para os cursos de nível médio e de graduação, é exigido que o candidato tenha concluído o ensino médio. Este estudo aborda a primeira oferta de cursos MOOC gamificados realizada no ano de 2016.

\section{Gamificação em cursos online}

Fardo (2013) explica que a gamificação consiste em utilizar elementos de jogos (mecânicas, estratégias, pensamentos) fora de seus contextos, com o objetivo de motivar os indivíduos a agir, auxiliando na resolução de problemas e promovendo o aprendizado. O fenômeno vem se difundindo pela educação e sendo aplicado como estratégia de ensino e de aprendizagem, produzindo resultados positivos através das experiências (FARDO, 2013; SHELDON, 2011).

A gamificação está se tornando cada vez mais popular porque apresenta uma forma de engajamento capaz de despertar a motivação e estimula o desejo pela aprendizagem nos alunos. O processo de gamificação pode ajudar a desenvolver uma experiência de ensino mais intuitiva e prazerosa (FREIRE, 2015). A fim de tentar obter um melhor grau de envolvimento e motivação do aluno, a gamificação usa elementos tradicionalmente encontrados em jogos como: sistema de feedback, sistema de recompensas, competição, objetivos, regras claras, níveis, tentativa e erro, etc. (FARDO, 2013). É importante entender que a gamificação não implica em criar um jogo que resolva o problema recriando a situação dentro de um mundo virtual, mas utilizar as mesmas estratégias, métodos e pensamentos usados ??para resolver esses problemas de mundos virtuais em situações do mundo real (FARDO, 2013). Quadros (2014) afirma que o uso da gamificação em cursos online pode motivar os alunos a participar mais profundamente.

\section{Gamificação no AVEA Moodle}

Para a realização deste estudo, além dos conceitos que envolvem gamificação, é necessário entender como ocorre o funcionamento dos cursos ofertados. No caso do modelo de curso online proposto, a primeira tarefa foi garantir que o curso pudesse ser institucionalizado usando a plataforma Moodle. Portanto, foi necessário realizar uma 
análise a fim de conhecer as possibilidades que o Moodle oferece para a gamificação. Existem vários plugins ou ferramentas para o Moodle que podem ser utilizados na elaboração de um curso. No caso dos plugins, destacamos os blocos Ranking, Level Up, Stash e Game (MOODLE, 2017). Segundo Moodle (2017), o bloco Ranking apresenta a perspectiva de competição entre os participantes, destacando aqueles que apresentam melhor desempenho. Level Up permite que os alunos passem por fases, onde depois de obter uma pontuação, o participante avança nos níveis. Outra opção é o Stash que permite imagens ocultas no conteúdo do curso que os alunos devem encontrar para concluir o curso. Por fim, Game apresenta um conjunto de jogos tradicionais que têm o comportamento de atividades. Usando tal opção, os professores podem utilizar o jogo da forca, palavras cruzadas, Sudoku, caça-palavras, entre outros. Todos esses plugins são complementos que precisam ser adicionados à versão do Moodle original (MOODLE, 2017).

No entanto, algumas opções de gamificação podem ser encontradas na versão original do Moodle, entre as quais há destaque para:

- Badges consistem em medalhas, podem ser atribuídas manualmente ou automaticamente pelo sistema. A opção manual propicia maior flexibilidade, já que cabe ao professor atribuí-lo ao aluno ou não, porém não se mostra eficaz para grupos com grande número de alunos. A opção automatizada é limitada apenas aos casos de conclusão de uma atividade em uma data especificada. Os badges podem ser apresentados em um bloco disponível na página inicial do curso ou dentro do perfil do aluno.

- Restrição é um recurso que permite que uma atividade seja exibida ou ocultada a partir de alguma regra pré-estabelecida. As regras podem estar em um conjunto de possibilidades e usar conectores e / ou estarem vinculadas a:

- Conclusão da atividade: exige que o aluno conclua (ou não conclua) outra atividade.

- Data: está vinculada a uma uma data e hora que devem ser especificadas.

- Nota: exige que os alunos alcancem uma nota específica.

- Perfil de usuário: controle de acesso com base nos campos que estão no perfil do aluno.

Além das possibilidades apresentadas, as versões mais recentes do Moodle contam com: Grupo: Verifica se o aluno está em um grupo; Idioma: verifica o idioma em que o curso está sendo exibido; e Grupo de restrição: adicione um grupo de restrições nas quais a lógica complexa será aplicada.

No contexto da gamificação, as restrições podem ser combinadas com o recurso de rótulos, desempenhando um papel semelhante aos badges. 
Para o presente estudo, as opções relatadas foram estudadas e as possibilidades e 0 alinhamento da técnica de recompensa explorada. $O$ estudo realizado oportunizou conhecer que as Restrições seriam as opções mais adequadas para o modelo de curso proposto, uma vez que identificou ser possível atrelar as recompensas ao cumprimento de uma ação do estudante e, assim, construir um ambiente gamificado. Além disso, a restrição oferece maiores possibilidades de configuração e, em particular, automação de recompensas. Como resultado, foram determinadas as regras mostradas no Quadro 1.

\begin{tabular}{|c|c|c|c|c|}
\hline & Emblema & Regra & Recompensa & $\begin{array}{l}\text { Identificaçăo } \\
\text { no Moodle }\end{array}$ \\
\hline \# & $\begin{array}{l}\text { Procura-se } \\
\text { candidato }\end{array}$ & Preencheu o formulário do estudante & & Automático \\
\hline 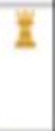 & Jogador consciente & Leu as regras do curso & $\begin{array}{l}\text { Conteúdos } \\
\text { da } \\
\text { instituiçâo }\end{array}$ & Automático \\
\hline 吾 & $\begin{array}{l}\text { Conhecedor } \\
\text { da instituição }\end{array}$ & Leu ou assistiu aos conteúdos & & Automático \\
\hline צ & $\begin{array}{l}\text { Estudante } \\
\text { dedicado - } \\
\text { bronze }\end{array}$ & Dedicou 10 horas ao curso & $\begin{array}{l}\text { Nova tentativa } \\
\text { disponivel }\end{array}$ & Manual \\
\hline 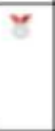 & $\begin{array}{l}\text { Dedicação do } \\
\text { estudante - } \\
\text { prata }\end{array}$ & Dedicou 20 horas ao curso & $\begin{array}{l}\text { Nova tentativa } \\
\text { disponivel }\end{array}$ & \\
\hline 8 & $\begin{array}{l}\text { Dedicação do } \\
\text { estudante - } \\
\text { ouro }\end{array}$ & Dedicou 30 horas ao curso & $\begin{array}{l}\text { Nova tentativa } \\
\text { disponivel }\end{array}$ & \\
\hline$=$ & $\begin{array}{l}\text { Estudioso da } \\
\text { Matemática }\end{array}$ & $\begin{array}{l}\text { Completou os } 5 \text { questionários de } \\
\text { Matemática }\end{array}$ & \multirow{4}{*}{$\begin{array}{l}\text { Feedback } \\
\text { personalizado } \\
\text { nesta área. } \\
\text { Novos } \\
\text { questionários } \\
\text { de exames } \\
\text { anteriores da } \\
\text { instituiçăo }\end{array}$} & \multirow[t]{4}{*}{ Automático } \\
\hline \pm & $\begin{array}{l}\text { Estudioso da } \\
\text { Matemática }\end{array}$ & $\begin{array}{l}\text { Completou os } 5 \text { questionários de } \\
\text { Natureza }\end{array}$ & & \\
\hline a & $\begin{array}{l}\text { Especialista em } \\
\text { Humanas }\end{array}$ & $\begin{array}{l}\text { Completou os } 5 \text { questionários de } \\
\text { Humanas }\end{array}$ & & \\
\hline 호 & $\begin{array}{l}\text { Estudioso da } \\
\text { Linguagens }\end{array}$ & $\begin{array}{l}\text { Completou os } 5 \text { questionários de } \\
\text { Linguagens }\end{array}$ & & \\
\hline (2) & $\begin{array}{l}\text { Curioso por } \\
\text { Matemática }\end{array}$ & $\begin{array}{l}\text { Respondeu } 2 \text { ou mais questōes no } \\
\text { fórum de Matemática }\end{array}$ & \multirow{4}{*}{$\begin{array}{l}\text { Novos } \\
\text { questionários } \\
\text { desta área de } \\
\text { exames } \\
\text { anteriores da } \\
\text { instituição }\end{array}$} & \multirow[t]{4}{*}{ Automático } \\
\hline 0 & $\begin{array}{l}\text { Curioso por } \\
\text { Natureza }\end{array}$ & $\begin{array}{l}\text { Respondeu } 2 \text { ou mais questōes no } \\
\text { forum de Natureza }\end{array}$ & & \\
\hline $\boldsymbol{\theta}$ & $\begin{array}{l}\text { Curioso por } \\
\text { Humanas }\end{array}$ & $\begin{array}{l}\text { Respondeu } 2 \text { ou mais questōes no } \\
\text { forum de Humanas. }\end{array}$ & & \\
\hline Q & $\begin{array}{l}\text { Curioso por } \\
\text { Linguagens }\end{array}$ & $\begin{array}{l}\text { Respondeu } 2 \text { ou mais questōes no } \\
\text { förum de Linguagens }\end{array}$ & & \\
\hline 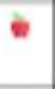 & $\begin{array}{l}\text { Ajudante do } \\
\text { professor }\end{array}$ & $\begin{array}{l}2 \text { ou mais perguntas respondidas em } \\
\text { cada fórum }\end{array}$ & $\begin{array}{l}\text { Nova tentativa } \\
\text { disponivel }\end{array}$ & Automático \\
\hline 62 & $\begin{array}{l}\text { Compartilhador de } \\
\text { conhecimento }\end{array}$ & $\begin{array}{l}2 \text { ou mais links compartilhados com } \\
\text { colegas }\end{array}$ & $\begin{array}{l}\text { Nova tentativa } \\
\text { disponivel }\end{array}$ & Automático \\
\hline 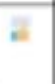 & $\begin{array}{l}\text { Preparado para a } \\
\text { prova }\end{array}$ & Completou todos os questionários & & Automático \\
\hline
\end{tabular}

Quadro 1: regras do curso

elaboração própria (2017)

Cada linha mostra o emblema visual usado para cada regra, além de apresentar a 
recompensa e como a regra foi construída no Moodle.

Além das regras do curso, foi necessário especificar uma regra de conclusão para os alunos obterem o certificado do curso. Portanto, considerando os requisitos mínimos, a duração e a meta do curso, cada aluno precisou realizar pelo menos um questionário de cada área, sendo que foram disponibilizados ao menos 5 questionários para cada área. Assim, a seção seguinte apresenta o processo de gamificação do curso na prática.

\section{Desenho do curso com uso da gamificação}

Foram ofertados três cursos, que tiveram o mesmo modelo pedagógico. Cada um trabalhou com conteúdos específicos e buscou atingir pessoas interessadas em cursos de ensino médio, subsequentes e superior. No geral, os três cursos tinham uma estrutura semelhante composta por 6 módulos. O primeiro módulo explicava 0 funcionamento do curso e solicitava informações sobre os alunos, tais como nível de escolaridade, papel (se aluno ou professor da instituição) e buscava conhecer cursos que os participantes pretendiam realizar no futuro. Ao fornecer esses dados, os alunos foram recompensados ??com o desbloqueio do conteúdo do curso e ganharam um distintivo de prêmio. Os emblemas foram exibidos na área inferior da página inicial do Moodle, na qual os alunos poderiam conferir os prêmios concedidos, como mostra a Figura 1.

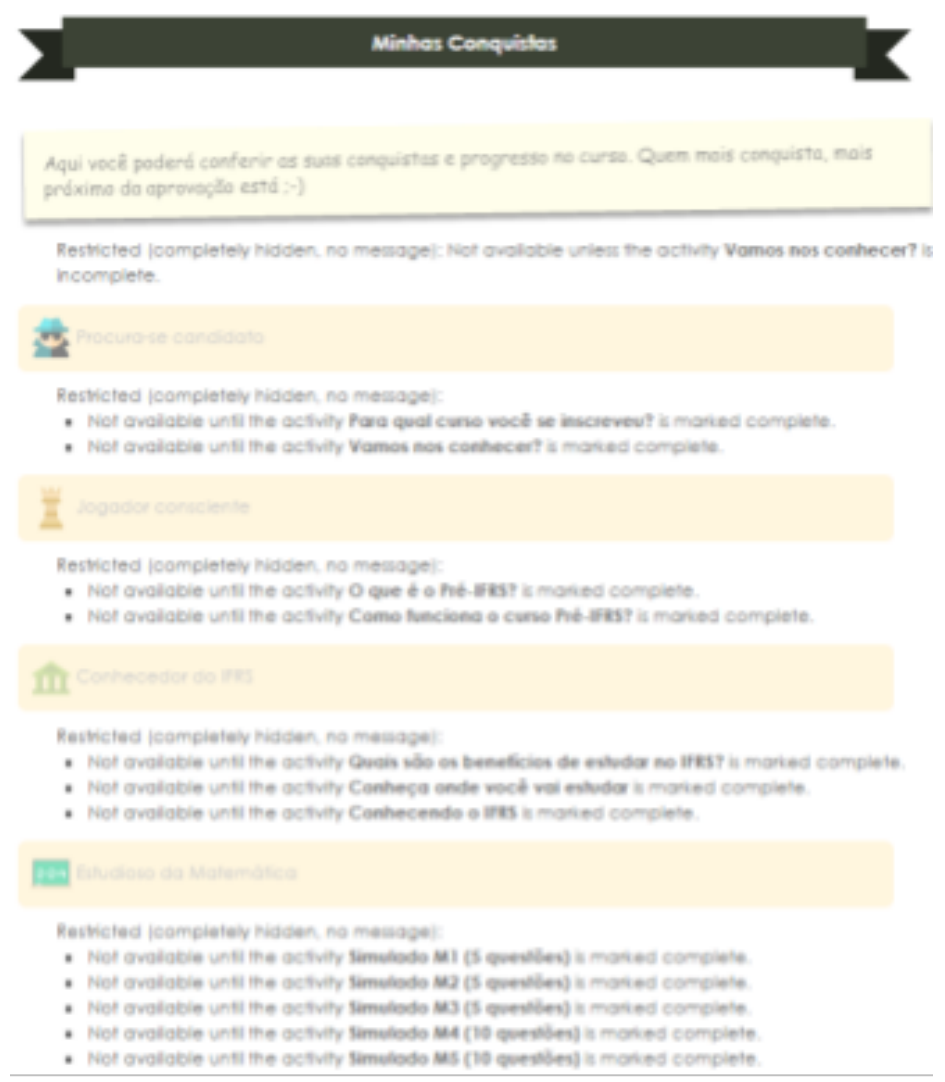

Figura 1. Exemplo de Gamificação usando Regras de Restrição do Moodle elaboração própria (2017) 
$\mathrm{Na}$ segunda parte, os alunos tiveram acesso a informações sobre o IFRS e sobre o processo seletivo para ingresso. Os conteúdos foram apresentados de forma interativa e após a conclusão desta etapa, os alunos receberam um novo emblema.

Em seguida, foram apresentados os módulos relacionados a cada uma das quatro áreas: Matemática, Ciências da Natureza, Ciências Humanas e Idiomas. Inicialmente, cada área ofereceu cinco questionários para todos os alunos. De acordo com o progresso individual, foram apresentados conteúdos extras, como questionários, ensaios e listas de verificação. Também foi ofertado um fórum onde os alunos puderam postar suas dúvidas e contar com ajuda dos tutores ou dos próprios colegas, esses que ganhariam emblemas caso contribuíssem com os tutores na solução das dúvidas do fórum. A Figura 2 ilustra um recorte do curso e as regras aplicadas.

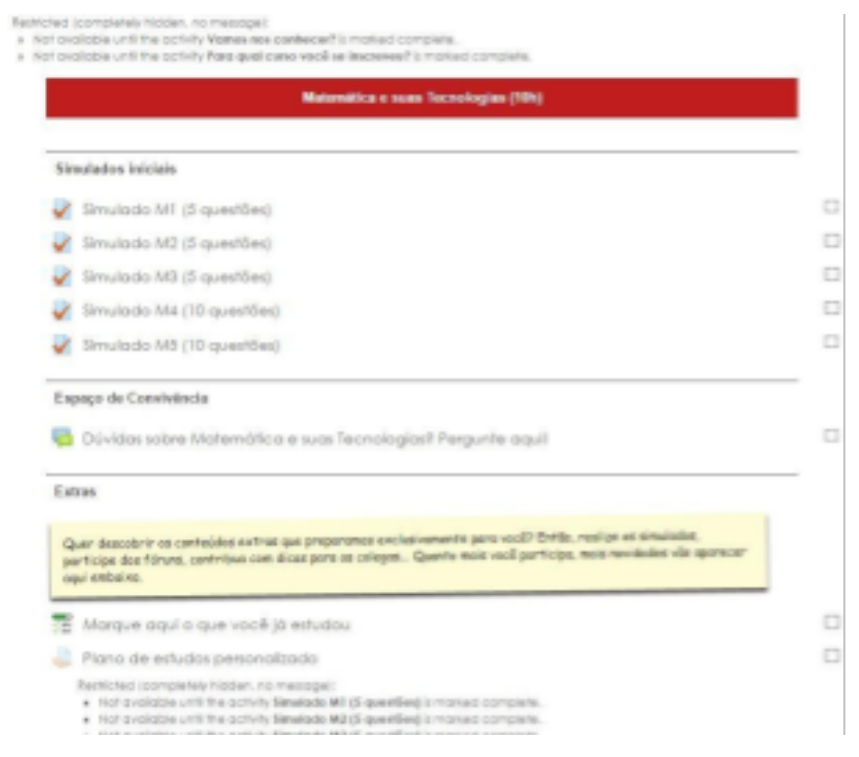

Figura 2: Conteúdos do curso

elaboração própria (2017)

O modelo pedagógico dos cursos contou com abordagem centrada no aluno, fato que favorece o protagonismo discente e estimula suas ações em busca do conhecimento, uma vez que o progresso no curso está atrelada a conclusão de módulos anteriores, cujo tempo e organização depende da ação dos estudantes.

\section{Resultados}

Além da preparação dos três cursos, foi organizado um curso específico para os tutores que ajudariam os alunos. Os tutores foram voluntários, inscritos previamente à oferta do curso, e como requisito para atuação era necessário ter graduação em uma das quatro áreas apresentadas nos cursos: Matemática, Ciências da Natureza, Ciências Humanas e Idiomas. O curso preparatório dos tutores contou com quatro módulos, a saber: 
Conhecendo o IFRS, Processo Seletivo e o curso Pré-IFRS parte 1, Moodle para Tutores e Processo Seletivo e o curso Pré-IFRS parte 2. O curso buscou capacitar os tutores em questões específicas sobre regras de gamificação, o papel da tutoria, questões sobre a instituição e seu processo de ingresso, necessárias para o caso de dúvidas dos estudantes. Um grupo de 100 tutores se inscreveu no curso e 11 foram aqueles que o concluíram.

Os três cursos ofertados do Pré-IFRS no ano de 2016 foram destinados a pessoas que haviam se inscrito no processo seletivo do IFRS. No ano deste estudo, a instituição recebeu 1.318 inscrições, dentre as quais 517 foram realizadas por quem estava se preparando para ingresso no ensino médio, 194 para cursos de nível médio (subsequentes) e 510 inscrições para quem estava almejando o ingresso em cursos de graduação. A Tabela 1 apresenta o número de inscritos e concluintes no referido curso.

\begin{tabular}{|c|c|c|c|c|c|c|}
\hline Nome do curso & Tutoria & $\begin{array}{c}\text { Modelo } \\
\text { pedagógico }\end{array}$ & Oferta & $\mathrm{CH}$ (hs) & Inscritos & Concluintes \\
\hline $\begin{array}{l}\text { Pré-IFRS: candidatos } \\
\text { para os cursos } \\
\text { Tecnicos Integrado / } \\
\text { Concomitante ao } \\
\text { Ensino Medio }\end{array}$ & Automatizada & Centrado no aluno & 2016 & 45 & 514 & 224 \\
\hline $\begin{array}{l}\text { Pre-IFRS: candidatos } \\
\text { para os cursos } \\
\text { Tecnicos Subsequente } \\
\text { ao Ensino Medio }\end{array}$ & Automatizada & Centrado no aluno & 2016 & 45 & 194 & 29 \\
\hline $\begin{array}{l}\text { Pré-IFRS: candidatos } \\
\text { para os cursos } \\
\text { Superiores }\end{array}$ & Automatizada & Centrado no aluno & 2016 & 45 & 510 & 91 \\
\hline \multirow[t]{2}{*}{ Pré-IFRS: TUTORES } & Automatizada & Centrado no aluno & 2016 & 100 & 100 & 11 \\
\hline & & & & Total & 1318 & 355 \\
\hline
\end{tabular}

Tabela 1. Inscritos e concluintes

Fonte: elaboração própria (2017)

Para realizar o curso, todos os alunos deveriam preencher algumas informações sobre si mesmos e ler as regras do curso, a fim de obter mais questionários (regras do jogo) e concluir o curso (regras do curso). Além das ferramentas automatizadas para atividades, especialmente a partir dos questionários, os alunos receberam apoio dos tutores, esses 
que receberam um grupo de alunos para ajudar e acompanhar por meio de orientação pessoal e mensagens encorajadoras. No final, 355 alunos concluíram o curso de acordo com as regras, o que resulta em um total de $27 \%$ do número total de inscritos. No entanto, a partir da análise das interações em relatórios específicos, foi possível perceber que muitos estudantes não acessaram o curso para completá-lo, mas para ter acesso a conteúdos específicos e realizar atividades em áreas que tinham mais mais domínio ou mais dificuldades.

O curso atingiu ao objetivo proposto e demonstrou ser possível aplicar a técnica de recompensa a partir da utilização de questionários com uso das Restrições no Moodle, fatores que contribuíram para efetivação de um curso gamificado, massivo, aberto e online.

\section{Considerações finais}

A pergunta original de pesquisa definida como "É possível criar um curso usando técnicas de Gamificação no Moodle, considerando um grande número de alunos?" foi respondida e a implementação do modelo de curso apresentado neste estudo mostrou que é possível utilizar técnicas de Gamificação no Moodle, especialmente a partir da configuração de Restrições nas ferramentas do Moodle com uso de questionários. Estudos similares que pretendam fazer uso de estratégias de jogo, podem considerar a utilização de plugins juntamente com a versão do Moodle.

A realização deste estudo demonstra que é possível ofertar cursos massivos no Moodle e que a ferramenta questionário apresenta grandes contribuição para automatização de atividades e para atrelar as configurações de Restrições a apresentação de emblemas. Recentemente, uma universidade lançou sua plataforma para Cursos MOOC usando o Moodle, o que ratifica a utilização desse ambiente para cursos com características dos MOOCs (LUMINA, 2016).

Trata-se de um estudo preliminar que não considerou informações sobre a participação dos alunos (em conteúdo original e extra fornecidos pela realização no curso), o progresso, o tempo investido ou as áreas que estudaram. Esses elementos podem ser objeto de estudos futuros, especialmente se atrelados a uma análise do acompanhamento sobre os conceitos apreendidos, suas expectativas e motivações, fatores que podem contribuir para qualificar o modelo proposto. Há de se considerar, ainda, estudos sobre as taxa de retenção e conclusão para alunos que já estão matriculados.

\section{Referências}

BURGE, J. et al. (2015) SPOCs: What, Why, and How. In: Proceedings of the 46th ACM Technical Symposium on Computer Science Education. ACM. p. 595-596.

FARDO, M. L. (2013). A gamificação aplicada em ambientes de aprendizagem. Renote, 
Porto Alegre. v. 11, n. 1. 2013.

FERNANDES, K. T.; MARTINS, R. S. Gamificação como Fator Motivacional para Diminuição das Taxas de Evasão nos MOOC. Disponível em: . Acesso em: nov, 2016. FOX, A. (2013). From moocs to spocs. Communications of the ACM, v. 56, n. 12, p. 38-40.

FREIRE, C. C. (2015) Gamificação e EaD: importância e possibilidades para uma educação com foco no aluno. 31 folhas, TCC (Pós-graduação em Planejamento, Implementação e Gestão da EAD) - Universidade Federal Fluminense, campus Paracambi, Rio de Janeiro. 2015.

KRAUSE, M. et al. (2015). A playful game changer: Fostering student retention in online education with social gamification. In Proceedings of the Second (2015) ACM Conference on Learning@ Scale (pp. 95-102). ACM.

LEE, Y., CHOI, J. (2011). A review of online course dropout research: Implications for practice and future research. Educational Technology Research and Development, 59(5), 593-618.

LUMINA. (2016) Repositório Lumina: online e gratuito. Disponível em $<$ https://lumina.ufrgs.br/> . Acesso em nov, 2016.

MOODLE. Plugins (2016). Disponível em <https://moodle.org/plugins/block_stash>. Acesso em nov, 2016.

NAWROT, I.; DOUCET, A. (2014). Building engagement for MOOC students: introducing support for time management on online learning platforms. In Proceedings of the 23rd International Conference on World Wide Web (pp. 1077-1082). ACM. nov, 2016.

OVERBY, K. (2011) Student-Centered Learning: ESSAI: The College of DuPage Anthology of Academic Writing across the Curriculum, v. 9, n. 32, p. 109-112.

QUADROS, G. B. F. (2014). As affordances motivacionais da gamificação na EAD. In Anais do Congresso Nacional Universidade, EAD e Software Livre (Vol. 2, No. 5).

SHELDON, L. (2011). The multiplayer classroom: Designing coursework as a game. Cengage Learning. 